\title{
The Physical Fitness Monitoring and Recovery Plan of Elite Marathon Runners
}

\author{
XiaoTang Li, ZhiLiang Zeng, Luo Ying \\ dept. of PE, Lanzhou University of Technology, Lanzhou, China
}

\begin{abstract}
Based on the long-term physiological and biochemical indexes monitoring and analysis of male elite athletes from Marathon sports teams in Gansu Province, this paper summed up the physical fitness moni oring indicators of these Marathon athletes (anaerobic threshold, heart rate, blood routine examination, urine routine examination, serum biochemistry $\mathrm{CK}, \mathrm{BUN}$ ) and nutritional recovery methods (sports nutrition, food, and other physical methods) in the training period, trying to provide reference for coaches to timely monitor runners' functional the functional condition.
\end{abstract}

KEYWORD: Marathon; Physical fitness; Recovery

Marathon is the cyclical sports. The running speed of Marathon is not very high, but the exercise strength is medium. Because of the very long distance running and last about 2 hours, Marathon is the typical sports which imply aerobic metabolism. The aerobic metabolism about glycogen and fat provide the most energy for Marathon runners.

\section{RESEARCH OBJECT AND METHODS}

\subsection{Research object}

Take the elite runners in men's marathon sports team of Gansu province as the research object.

\subsection{Research Methods}

1.2.1 Literature Material Consult: Consulted a number literature material which are related to marathon training and high altitude, sub-altitude training biochemical parameters.

1.2.2 Measurement method: in different training period, physiological and biochemical indicators of runners were monitored, finally the accumulated data were statistically analyzed.

1.2.3 Observation method: having meticulous observation for training status and mental performance of runners.

\section{ANALYSIS AND DISCUSSION}

\subsection{The Physical Monitoring Indicators of Marathon Runners}

\subsubsection{Anaerobic Threshold}

Marathon often use anaerobic threshold test to reaction athlete athletic ability, and guide training and test training effect. Marathon runners as the running speed of closing to the anaerobic threshold, especially at the anaerobic threshold running speed of $97 \% \sim 103 \%$ to training is most effective. In this running speed, the effect is acting on the large number of muscle fibers, a proportion of raising the fast-twitch fibers is high and the metabolism is active, the number of using oxygen is increased.

\subsubsection{Heart Rate}

Long-term monitoring of Morning Pulse, when the morning pulse returned to the range of normal that we are referenced as usual, it is indicated that the body has been restored; If it was significantly higher than normal levels, it should be noted that athletes may have occur fatigue, the appropriate strengthen recovery should be taken.

\subsubsection{Blood routine (BT)}

Blood routine mainly refers to the Hemoglobin monitor. After the training, the athletes functional recovery was showed that hemoglobin slightly elevated or maintain the original level or slightly lower $(2-3 \mathrm{~g} / \mathrm{dl})$ normal level; if it is significantly dropped, it showed that the body fatigue and 
regeneration is affective, you should take timely recovery means.

At the same time, you should pay attention to the changes of white blood cells, high intensity training caused immune function decreased, if the white blood cells is below normal levels that should strengthen nutrition means and target to improve immunity, in order to prevent illness before; if it above the normal range, you should check whether the athletes infection.

\subsubsection{Routine Urine}

The main monitoring indicators are urine protein and urine occult blood. Urinary protein after exercise is mainly used to monitor training intensity, the next day morning urine protein situation reflects the recovery of athletes function.

\subsubsection{Serum biochemical (CK, BUN)}

Compared to other projects, in Marathon training the degree of mechanical damage to muscle heavier, on the one hand skeletal muscle bear long time and heavy load of movement, on the other hand the body and ground friction are greater. So in addition to using the nutrition means to decrease the muscle fatigue, but also strengthen the physical therapy and rehabilitation for athletes foot mechanical damage, .

Urea nitrogen have a close relationship with physical activity and body protein metabolism, marathon athletes often under the long-term training, so the next morning urea nitrogen can be integrated to reflect the degree of physical adaptation and recovery. Such as urea nitrogen recovery lever has not yet returned to normal levels may be related to the body's can not suit for the loading dose and sugar reserves shortage. It can though carbohydrate supplement to alleviate the problem of high blood urea nitrogen.

\section{THE NUTRITIONAL CHARACTERISTICS AND RECOVERY PLAN OF MARATHON RUNNERS}

\subsection{The Marathon runner's characteristics of nutrient requirements}

Recovery and carbohydrates: the training is proceed once a day or twice a day need recovery strategy, especially when two hard training followed by progress. Most of the long-distance runners may find that the typical Western diet is not able to provide enough energy for the marathon training. In fact, many long-distance runners "occur knocking" (energy exhaust)in the first time when their large amount of training proceeding in the first week, the cause is not able to progressive store enough muscle glycogen levels.
The time of carbohydrate supplement for recovery is vital after the long-time and high intensity training or running. Not just sugar depletion of muscle, running also lead to the damage of muscle fiber, which will delay the recovery of glycogen. If the runners can absorb the carbohydrates immeditely after the training or competition, it will make sure that athletes can meet the needs of carbohydrate at the beginning of the next training.

\subsubsection{Lack of Iron element}

Marathon runners, especially female athletes often in danger of low iron elements condition. It is caused by many reasons, including the loss of iron caused by sweating, gastrointestinal hemorrhage, the destruction and loss of red cell, low iron intake and the menstrual of female athletes loss blood. According to the reports, it seems that many longdistance runners intake adequate iron from dietary, but from the latest examination shows that these numerical may be based on the food, but they can not be fully absorbed. A sports doctor can help to ensure whether the athletes is in conditions of low iron storage.

\subsubsection{Gastrointestinal problems}

Many long-distance runners in the running process of hard training, especially in match reports that exist the gastrointestinal problems. If athletes suffer from stomach cramps or diarrhea, it is difficult to get a good score. At the end, some of them will experience some problems, such as hiccups and heartache. Some athletes even found that they bleeding in the game. The reason for these problems is not clear, but may be related to the Intensity of running and the competition pressure, perhaps related to over-hydration or dehydration. Some athletes can point to specific food caused these problems, but most of the athletes can not be determined. Perhaps the general direction is try their best to suit their consumption of the type of food and the time before the running.

\subsubsection{Liquid supplement in the training}

Athletes may have dehydration because they will sweat a lot during the long-distance running, so before, during, and after exercise should take a reasonable amount of fluid solution to keep internal environment stable. Supplemented drinks with lower sugar in favor of gastric emptying and enhance athletic ability in the sport that will sweat a lot. Profuse sweating also makes the body electrolyte loss, loss of electrolytes can be added before or after exercise, part of electrolyte is also can available in the supplement drinks during exercise. Influenced athletes water intake in training or competition the main reason is that when players trying to multi rehydration may cause abdominal fullness feeling, 
partly due to the moisture absorption rate reduce in movement.

A principle of liquid supplement in training is a few times, it is best to use a sports drink and can not supplement whitewater. Studies suggest that longdistance runners initiative liquid intake no more than hourly $500 \mathrm{ml}$ in the race.

International Amateur Athletic Federation (IAAF) advocated that in all $10 \mathrm{~km}$ and above $10 \mathrm{~km}$ competitions can drink sugary electrolyte drinks to supply enough water, sugar and electrolytes to replenish energy and sweat loss. The amount of liquid lost depends on the wicking rate, which is proportional to the athlete metabolic rate and the ambient temperaturel.

\subsection{Nutritional Recovery Plan Of Elite Marathon Runners}

\subsubsection{Nourishment recovery means}

Table 1The Nutrition Recovery Methods of Marathon Runners

\begin{tabular}{|c|c|c|}
\hline Usage time & Product portfolios & Function and effect \\
\hline \multirow{3}{*}{$\begin{array}{l}\text { After getting up } \\
\text { in the morning }\end{array}$} & $\begin{array}{l}\text { Ting / WeiTing Oral } \\
\text { Solution }\end{array}$ & $\begin{array}{l}\text { Use two bottles of Ting / WeiTing oral solution before breakfast, mainly used to } \\
\text { improve testosterone levels and promoting athletes regeneration. }\end{array}$ \\
\hline & $\begin{array}{l}\text { Changbai Jing Faerie } \\
\text { (day) }\end{array}$ & $\begin{array}{l}\text { Use two bottles of Changbai Jing Faerie before breakfast, is mainly used to improve } \\
\text { the hemoglobin and testosterone levels, promoting regeneration and strengthening of } \\
\text { the athletes aerobic capacity }\end{array}$ \\
\hline & $\begin{array}{l}\text { Acclerate } \\
\text { Hematopoiesis } \\
\text { Centrum }\end{array}$ & $\begin{array}{l}\text { One piece of Acclerate Hematopoiesis Centrum with breakfast, it is mainly for } \\
\text { athletes to supply the iron loss and prevent the hypochrosis occur, and increase the } \\
\text { supply capacity of aerobic energy. }\end{array}$ \\
\hline \multirow{3}{*}{$\begin{array}{l}\text { Before training } \\
\text { / competition }\end{array}$} & $\begin{array}{l}\text { Comepelex Energy } \\
\text { Drink }\end{array}$ & $\begin{array}{l}\text { Before sports and exercise, adequately Supplying sugar, protecting muscle glycogen } \\
\text { reserves, delay fatigue occurred. }\end{array}$ \\
\hline & $\begin{array}{l}\text { Active Capbohydrate } \\
\text { Capsule }\end{array}$ & Four granules of Active Capbohydrate Capsule before strength training \\
\hline & Salt Stick & $\begin{array}{l}\text { Two pills each time. Athletes may have dehydration because they will sweat a lot } \\
\text { during the long-distance running, you should catch up on salt, maintain muscle } \\
\text { contraction. }\end{array}$ \\
\hline \multirow{3}{*}{$\begin{array}{l}\text { After training / } \\
\text { competition }\end{array}$} & $\begin{array}{l}\text { Soybean Peptides } \\
\text { Powder }\end{array}$ & \multirow{3}{*}{$\begin{array}{l}\text { These types of supplements should combine to used, it is mainly for muscle } \\
\text { problems, replenish protein material and reduce muscle breakdown (decreases the } \\
\text { degree of CK increases after the strength training). }\end{array}$} \\
\hline & $\mathrm{CPT}$ & \\
\hline & Glutamine CapsuleS & \\
\hline \multirow{2}{*}{$\begin{array}{l}\text { After supper } \\
\text { /before sleep }\end{array}$} & $\begin{array}{l}\text { Ting / Wei Ting oral } \\
\text { solution }\end{array}$ & $\begin{array}{l}\text { Use two bottles of Ting / WeiTing oral solution before bedtime, it is mainly used to } \\
\text { improve testosterone levels and promoting athletes regeneration. }\end{array}$ \\
\hline & $\begin{array}{l}\text { Changbai Jing } \\
\text { Faerie(night) }\end{array}$ & $\begin{array}{l}\text { Use two bottles of Changbai Jing Faerie before bedtime, it is mainly used to improve } \\
\text { the hemoglobin and testosterone levels, promoting regeneration and strengthening of } \\
\text { the athletes aerobic capacity }\end{array}$ \\
\hline
\end{tabular}

\subsubsection{Other means of recovery}

\subsubsection{1 training methods}

Doing finishing activities after training, such as small amount of aerobic exercise (such as relaxation running, climbing, etc.), the muscles fully stretched.

\subsubsection{2 physical means}

Athletes mutual relaxing massage, Cold compresses major muscle (do not let the ice directly contact with the skin,it may cause frostbite), do hot water bath (and combine with ice compresses to promote the circulation and to accelerate the elimination of acidic metabolites) (Marathon is a long time training, so foot wear heavy, high CK may also be the reason, it is recommended that do many appropriate ice compresses), and the means of appropriate physiotherapy.

\subsubsection{3 means of food supplements}

Increasing the intake of alkaline foods such as fresh vegetables (purple cabbage, cauliflower, celery, lettuce, radish sprouts, cabbage), fruit (pear, peach, citrus, apples), bacteria and algae (such as mushrooms, seaweed, etc.), milks and legumes (beans, bean sprouts, etc.), the amount of fructose and high-quality protein (such as complex energy drinks/ strong recovery powder, pure protein powder / peptide drinks, etc.) to relieve muscle soreness.

\section{SUMMARY}

Marathon as a sports items for human physical and will is a ordeal, in order to grasp the athletes functional state during training or competition, coaches or researchers should pay more attention to 
monitoring the indicators about physiological (anaerobic threshold, heart rate) and biochemical (blood, urine aspects, serum biochemistry).And take the sports nutrition, food and a variety of physical measures as an important means of recovery.

\section{REFERENCES}

[1] Lianshi Feng, Kaigang Li. Common Test Methods and Application about Evaluate Athletes' Biochemical Index. Beijing: Peoples Sports Publishing House, 2002.8: 25-75.

[2] Wangqing. The Research and Establish about Diagnosing and Monitoring Chinese Elite Athletes' Competitive ability and condition. Beijing: Peoples Sports Publishing House, 2004.2:5-10.
[3] Xiaofen Wang. Sports Statistics and SPSS Beijing: People's Sports Publishing House, 2002.12: 202-211.

[4] Dongliang Wang, Shenglin Zhang. Biochemical Indices of The Marathon Runner Zhu - hong LI in Sub-altitude Training Physical Education, 2009.6: 98-101.

[5] Qing Wang. Lianshi Feng, Qingzhang Weng. Training at the Highland Area, Beijing: People's Sports Publishing House, 2007.4: 88-102.

[6] Shenglin Zhang. The HB, BUN And CK Index Evaluation OF Male Middle Distance Runners in Gansu Province Before The Winter Training Gansu Associated University, 2007.7: 112-114.

[7] Shenglin Zhang, Dongliang Wang, Xiaotang Li. Annual (2007)Training Features and The Analysis of Exercise Stress about Chinese Elite Marathoner LI zhu - Hong Journal of Shandong Sports Institute, 2008.6.48-51. 